\title{
Long-Term Detection of Propofol Glucuronide in Urine Following Anesthetic Induction and Maintenance with Propofol
}

\author{
Joseph Salerno*, Joseph Jones, Mary Jones, Charles Plate, Douglas Lewis \\ United States Drug Testing Laboratories, Inc. (USDTL), Des Plaines, USA. \\ Email: ${ }^{*}$ joseph.salerno@usdtl.com \\ Received August $7^{\text {th }}, 2013$; revised September $9^{\text {th }}, 2013$; accepted September $21^{\text {st }}, 2013$ \\ Copyright (C) 2013 Joseph Salerno et al. This is an open access article distributed under the Creative Commons Attribution License, \\ which permits unrestricted use, distribution, and reproduction in any medium, provided the original work is properly cited.
}

\begin{abstract}
Propofol is the most commonly used compound for the intravenous induction and maintenance of anesthesia. Propofol addiction and abuse have become causes for concern in the healthcare community, especially among anesthesia and surgical professionals. The US Drug Enforcement Administration does not list propofol on any Schedules and most hospitals do not have inventory controls in place to prevent its misuse. Propofol is detectable in blood plasma as the parent compound for as much as 15 hours post-anesthesia. The metabolite propofol glucuronide (PPFG) has been detected in blood and urine as far out as 60 hours. Here we report the long-term renal excretion of PPFG in specimens from A) four participants following a 14-day course of orally ingested propofol dosing, and B) a female patient following anesthetic induction and 15 minutes' maintenance with propofol. Urinary PPFG was measurable well above limits of quantitation up to 6 days following oral ingestion and 28 days post-anesthesia. We also present a third set of data evaluating the likelihood of passive exposure to aerosolized propofol in the surgical environment by analyzing the levels of urinary PPFG of healthcare workers following operating room work shifts. The results presented here demonstrate that quantitation of PPFG in urinary samples is an efficient method of long-term screening for propofol misuse and abuse.
\end{abstract}

Keywords: Anesthetics; Drug Testing; Metabolism; Pharmacokinetics; Propofol; Propofol Glucuronide; Urine

\section{Introduction}

Propofol (2,6-diisopropylphenol; Diprivan ${ }^{\circledR}$, AstraZeneca Pharmaceuticals) is a fast-acting, short-duration, hypnotic agent that is administered intravenously for the induction and maintenance of general anesthesia [1]. With a quick recovery time following induction and minimal side effects [2], propofol has become the most widely used compound for intravenously administered general anesthesia [3]. Propofol rapidly enters the Central Nervous System, very smoothly induces unconsciousness, and undergoes swift metabolic clearance [4]. The highly lipophilic nature of propofol results in storage and slow release from deep tissue depots such as fat deposits and muscle tissues [5].

Although not traditionally seen as a drug of abuse, non-procedural misuse of propofol by anesthesiology and

"Corresponding author. surgical healthcare professionals with direct access to the compound has become a cause for concern [6]. Propofol abuse among healthcare professionals increased five-fold from 1997 to 2011, and despite a low incidence of abuse among anesthesia-based providers $(0.10 \%)$, the rate of fatality due to abuse is high (28\%) [6]. The fatality hazard of propofol abuse owes in great part to the compound's extremely narrow window of safety resulting from the rapid onset of unconsciousness during administration. The small difference between a therapeutic dose and a potentially hazardous dose that can cause acute respiratory depression creates a very real risk of fatal overdose if the drug is self-administered [7]. Propofol is not scheduled with the US Drug Enforcement Administration and $71 \%$ of surveyed anesthesia programs have no control system in place to secure and account for propofol supplies [6].

Propofol is metabolized in the liver where it is 
oxidized to 1,4-di-isopropyl quinol, and both propofol and quinol are subsequently conjugated to glucuronic acid and excreted in urine [8]. Total body clearance rates for propofol have generally been seen to exceed hepatic blood flow indicating other potential routes of clearance outside the liver $[4,8]$. Less than $0.3 \%$ of the parent compound is excreted unchangeably [9]. Whether this disappearance of native propofol in the excreted samples is indicative of complete metabolic destruction of or rapid sequestration in deep tissues has not been entirely characterized. Propofol glucuronide (PPFG) is the primary metabolite among at least seven major and minor metabolites, accounting for as much as $62 \%$ of recoverable conjugated propofol in urine specimens [9].

Post-mortem forensic protocols detect the use of propofol test for the parent compound in blood samples [10-14]. However, the brief serum half-life of propofol (21 - 56 minutes) [15] makes this approach unreliable for routine substance abuse testing. To our knowledge, the 15-hour profile of propofol in plasma seen by Bleeker et al. (2008) is the longest window of recovery of the parent compound reported for blood samples [8]. In the same report, Bleeker et al. detected urinary PPFG concentrations as far out as 60 hours post-anesthesia, suggesting that testing for propofol use in living subjects is more easily carried out by measuring PPFG concentrations in urinary specimens.

Here we report the long-term disappearance profile for urinary PPFG in specimens collected from a female patient over a 28-day period following routine procedural anesthetic induction and maintenance using propofol. Specimens were assayed for PPFG $(\mathrm{ng} / \mathrm{mL})$ by liquid chromatography tandem mass spectrometry (LC-MS/ MS), and PPFG levels were normalized to $100 \mathrm{mg} / \mathrm{dL}$ creatinine to account for changes in urinary output [16]. In addition, we discuss the findings from two of our unpublished pilot studies on urinary PPFG clearance, and the implications of all three datasets on the practice of routine screening for propofol misuse and abuse.

\section{Experimental}

\subsection{Ethics Statement}

The patient who provided specimens for this study is one of the authors and an employee of United States Drug Testing Laboratories (USDTL). Specimens provided for one of our pilot studies were submitted voluntarily by employees of USDTL. Specimens from the second pilot study were de-identified aliquots remaining from specimens referred to our lab for routine analysis and considered waste at the time of assay. Samples from USDTL employees were voluntarily given, and neither these nor the waste specimens required an ethics review.

\subsection{Subject History and Specimen Collection-Urinary PPFG Profile Following Propofol Anesthesia}

This study quantified the disappearance of PPFG in the urine of a female patient following anesthetic induction and maintenance with propofol during a routine colonoscopy examination. The patient was five feet and three inches tall $(1.6 \mathrm{~m}), 150 \mathrm{lbs} .(68 \mathrm{~kg})$, and age 45 - 50 years old. Propofol was administered intravenously in a total of $250 \mathrm{~mL}$ of fluid. A total of $300 \mathrm{mg}$ of propofol was administered, beginning with a $30 \mathrm{mg}$ induction. Anesthesia was maintained for 15 minutes following induction, and sedation lasted for 25 minutes. Propofol was tolerated well by the patient.

Thirteen urine specimens $\geq 10 \mathrm{~mL}$ in volume were collected from the subject periodically over a period of 28 days. The interval between specimen collections varied from 1 - 5 days. Urine was collected in $100 \mathrm{~mL}$ polypropylene specimen cups and stored at $2^{\circ} \mathrm{C}-8^{\circ} \mathrm{C}$ until tested. The patient's daily medications, taken orally prior to specimen collection, included $80 \mathrm{mg}$ acetylsalicylic acid (aspirin), $10 \mathrm{mg}$ pravastatin, $1000 \mathrm{mg}$ fish oil, $10 \mathrm{mg}$ cetirizine hydrochloride, $1500 \mathrm{mg}$ glucosamine, $1250 \mathrm{mg}$ chondroitin-sulfate, and a non-prescription multivitamin.

\subsection{Subject History and Specimen Collection-Pilot Study \#1: Urinary PPFG Profile Following Oral Ingestion of Propofol}

Pilot study \#1 measured the concentration of PPFG in urine samples taken from four USDTL employees who had ingested $50 \mathrm{mg}$ of propofol in gel-caps daily for 14 days. Following the 14 day ingestion, $\geq 10 \mathrm{~mL}$ samples were collected at irregular intervals as the subjects needed to void over a six day period, and tested for PPFG. Urine was collected in $100 \mathrm{~mL}$ polypropylene specimen cups and stored at $2^{\circ} \mathrm{C}-8^{\circ} \mathrm{C}$ until tested. The participants consisted of two males and two females between the ages of $45-65$ years and ranging in weight from $150-300$ lbs.

\subsection{Subject History and Specimen Collection-Pilot Study \#2: Urinary PPFG Resulting from Incidental Exposure}

Pilot study \#2 utilized de-identified aliquots remaining from specimens referred to our lab for routine analysis and considered waste at the time of assay. Personal information for the donors of these specimens is not available. The samples were originally collected from 27 certified registered nurse anesthetists immediately following the completion of 8 hour or longer work shifts in operating rooms where propofol was being administered 
to patients. The purpose of these samples was to test for PPFG levels in the urine of anesthesia professionals resulting from incidental exposure to aerosolized propofol during surgery.

\subsection{Chemical Reagents and Materials}

DRI $^{\circledR}$ Creatinine-Detect reagent was purchased from Microgenics Corporation (Fremont, CA, USA). The internal standard, propofol glucuronide- $d_{17}\left(\mathrm{PPFG}-d_{17}\right)$, was purchased from Toronto Research Chemicals (Toronto, ON, Canada). PPFG was purchased from Cerilliant Corporation (Round Rock, TX, USA). All solvents (HPLC grade) were purchased from Thermo-Fisher (Hanover Park, IL, USA). Anion exchange solid phase extraction columns (Quaternary Amine with chloride counter Ion, CUQAX12Z, $200 \mathrm{mg}$ bed, $10 \mathrm{~mL}$ cartridge) were purchased from United Chemical Technologies (Bristol, PA, USA).

\subsection{Quantification of Creatinine Concentration of Specimens}

Creatinine assays were quantified on an Olympus AU640 chemistry immunoanalyzer (Beckman Coulter, Inc., CA, USA) using DRI $^{\circledR}$ Creatinine-Detect reagent (Jaffe method; Microgenics Corporation, Fremont, CA, USA) [17].

\subsection{Preparation of Calibration Standards and Quality Control-PPFG}

Stock solutions of PPFG and PPFG- $d_{17}$ were prepared in methanol at a concentration of $100 \mu \mathrm{g} / \mathrm{mL}$. A PPFG spiking standard working solution $(0.40 \mu \mathrm{g} / \mathrm{mL})$ was prepared by further dilution with methanol. A PPFG- $d_{17}$ internal standard working solution $(0.40 \mu \mathrm{g} / \mathrm{mL})$ was prepared by dilution in methanol. A single-point calibrator $(20 \mathrm{ng} / \mathrm{mL})$ and a set of controls $(0,8,25$, and 80 $\mathrm{ng} / \mathrm{mL}$ ) were prepared by spiking $1 \mathrm{~mL}$ of certified negative urine in a $13 \times 100$ glass culture tube with an appropriate volume of PPFG spiking standard working solution.

\subsection{Specimen Preparation-PPFG}

Each specimen was prepared separately by accurately transferring $1 \mathrm{~mL}$ of urine to a $13 \times 100$ glass culture tube. $50 \mu \mathrm{L}$ of PPFG- $d_{17}$ internal standard was added to each specimen, calibrator or control and vortexed. The tubes were centrifuged at $3400 \times \mathrm{g}$ for 5 minutes. The samples were loaded onto the solid phase extraction columns that had been preconditioned with $2 \mathrm{~mL}$ of methanol, followed by $2 \mathrm{~mL}$ of deionized water. The samples were allowed to flow through the columns at 1
$\mathrm{mL} / \mathrm{min}$. The columns were washed with $2 \mathrm{~mL}$ of deionized water followed by $2 \mathrm{~mL}$ of methanol and then dried under full vacuum for one minute. Drugs were eluted from the columns into $13 \times 100$ glass tubes with 2 $\mathrm{mL}$ of methanolic formic acid (98:2) and evaporated under nitrogen at $40^{\circ} \mathrm{C}$. The dried residues were reconstituted with $100 \mu \mathrm{L}$ of deionized water by vortexing and analyzed by LC-MS/MS.

\subsection{LC-MS/MS Conditions-PPFG}

Urine specimens were analyzed using an Agilent Technologies 1200 system that consisted of a G1367D autosampler, a G1379B degasser, G1312B binary pump, and a G1310 isocratic pump (Wilmington, DE, USA). Separation was achieved using a Phenomenex Synergi RP (50 $\mathrm{mm} \times 2.0 \mathrm{~mm}, 2.0 \mu \mathrm{m}$ particle size) column held at $50^{\circ} \mathrm{C}$ in a G1316B Thermostatted Column Compartment (Wilmington, DE, USA). Using a flow rate of $0.25 \mathrm{~mL} / \mathrm{min}$, the solvent system was a gradient that consisted of A (deionized water $/ 0.1 \%$ formic acid) and B (acetonitrile $/ 0.1 \%$ formic acid). The solvent program held $\mathrm{B}$ at $32 \%$ from $0.0 \mathrm{~min}$ to $8.0 \mathrm{~min}$. The detector was an Agilent Technologies 6460 tandem mass spectrometer using electrospray ionization (ESI) in the negative mode (Wilmington, DE, USA). The capillary voltage was set at $4000 \mathrm{~V}$, the nozzle voltage set at $1000 \mathrm{~V}$ and the desolvation gas (nitrogen) was heated to $350^{\circ} \mathrm{C}$ with a flow of $10 \mathrm{l} / \mathrm{min}$. The sheath gas (nitrogen) was heated to $300^{\circ} \mathrm{C}$ and delivered at $12 \mathrm{l} / \mathrm{min}$. The internal standard (PPFG$d_{17}$ ) was monitored using the $\mathrm{m} / \mathrm{z} 370.2>193.9$ (quantification ion; Frag $=155 ; \mathrm{CE}=20)$ and $\mathrm{m} / \mathrm{z} 370.2>369.7$ (qualifying ion; Frag $=155 ; \mathrm{CE}=0$ ) transitions. The $\mathrm{m} / \mathrm{z}$ $353.2>176.5$ (quantification ion; Frag $=120 ; \mathrm{CE}=28$ ), the $\mathrm{m} / \mathrm{z} 353.2>112.6$ (quantification ion; Frag $=120 ; \mathrm{CE}$ $=12$ ) and $\mathrm{m} / \mathrm{z} 353.2>84.7$ (qualifying ion; Frag $=120$; $\mathrm{CE}=20)$ transitions were used to monitor PPFG where Frag is the Fragmentation Voltage (V) and CE is the Collision Energy (V). All data were processed using MassHunter B.02.01 (Wilmington, DE, USA).

\subsection{Identification Criteria-PPFG}

The identification criteria used for this procedure included four components: retention time, signal to noise, baseline resolution and relative ion intensity. The retention time of each analyte was required to be within $0.2 \mathrm{~min}$ of the calibrator. A signal to noise of greater than 3:1 was required of each ion chromatogram. A minimum of $90 \%$ return to baseline was required to consider a peak to be adequately resolved from a co-eluting peak. The relative ion intensity of the productions for each analyte (mass ratio) was required to be within $20 \%$ of the corresponding relative ion intensity of the calibrator. 


\section{Results}

Our limit of detection (LOD) in all three of these studies was $4 \mathrm{ng} / \mathrm{mL}$, and our limit of quantitation (LOQ) was 8 $\mathrm{ng} / \mathrm{mL}$. Creatinine secretion from muscles is relatively constant in an individual, and PPFG concentrations were normalized to $100 \mathrm{mg} / \mathrm{dL}$ creatinine levels to correct for differences in urinary production and flow-rate by the patient resulting from fluctuations in hydration levels [16].

Urine samples in the oral ingestion pilot study (pilot study \#1) were collected when the subjects needed to void, and as such occurred at irregular intervals (Table 1). We were only able to collect samples from subject \#2 for three days, and that subject's complete urinary PPFG profile was not available as a result. Subjects \#1, \#3, and \#4 all exhibited urinary profiles well above LOD/LOQ out to 5 - 6 days (120 - 154 hours) following the last oral dose. The urinary PPFG profile data of these subjects most nearly followed an exponential decay trend (Figure 1), however, this trend explains the behavior of the data only moderately well $\left(\mathrm{R}^{2}=0.681\right)$, likely due to the small size of our sample population and the wide range in physical variables of the subjects in the sample. None of the volunteers reported any anesthetic or euphoric feelings associated with ingesting propofol orally.

Of the de-identified nurse anesthetist samples from the second pilot study, only two samples measured above the LOD/LOQ (4.58 ng/mL and $17.34 \mathrm{ng} / \mathrm{mL}$; normalized to $100 \mathrm{mg} / \mathrm{dL}$ creatinine; Table 2). The average of the remaining 25 samples was $0.23 \mathrm{ng} / \mathrm{mL}$ over a range of $0.01 \mathrm{ng} / \mathrm{mL}$ to $2.20 \mathrm{ng} / \mathrm{mL}$ (normalized to $100 \mathrm{mg} / \mathrm{dL}$ creatinine).

Thirteen urine specimens were collected periodically from the colonoscopy patient over a period of 28 days post-anesthesia (Table 3). The disappearance profile for PPFG in this patient displayed an exponential decay trend $\left(\mathrm{R}^{2}=0.953\right.$; Figure 2). Surprisingly, PPFG was detectable at levels well above the LOD/LOQ for as long as 28 days post anesthesia.

\section{Discussion}

\subsection{Disappearance Profile of Urinary Propofol Glucuronide}

To our knowledge, only one other study has examined the long-term profile of urinary PPFG (Bleeker et al., 2008), which sampled blood and urine of patients out to 15 and 60 hours post-anesthesia respectively [8]. Based on urinary clearance rates and percentage of recovered PPFG, Bleeker et al. (2008) suggested that glucuronidation of propofol would require 5 - 6 days to reach completion and total clearance of propofol from the body, however, the post-colonoscopy results presented here
Table 1. Urinary propofol glucuronide following sub-therapeutic dosing by oral ingestion: pilot study \#1. .

\begin{tabular}{|c|c|c|c|}
\hline $\begin{array}{l}\text { Subject/Hours } \\
\text { Post Dosing }\end{array}$ & $\begin{array}{l}\text { PPFG } \\
(\mathrm{ng} / \mathrm{mL})\end{array}$ & $\begin{array}{c}\text { Creatinine } \\
(\mathrm{mg} / \mathrm{dL})\end{array}$ & $\begin{array}{c}\text { Normalized } \\
\operatorname{PPFG}^{2}(\mathrm{ng} / \mathrm{mL})\end{array}$ \\
\hline$\# 1 / 6$ & 3222 & 15.7 & 20,522 \\
\hline$\# 1 / 24$ & 1237 & 50.7 & 2440 \\
\hline$\# 1 / 36$ & 183 & 31.2 & 587 \\
\hline$\# 1 / 48$ & 300 & 65.2 & 460 \\
\hline$\# 1 / 72$ & 109 & 102.5 & 106 \\
\hline$\# 1 / 96$ & 45 & 136.2 & 33 \\
\hline$\# 1 / 120$ & 30 & 115.0 & 26 \\
\hline$\# 2 / 6$ & 33,119 & 132.2 & 25,052 \\
\hline$\# 2 / 24$ & 5819 & 257.7 & 2258 \\
\hline$\# 2 / 48$ & 761 & 149.6 & 509 \\
\hline$\# 2 / 72$ & 493 & 193.7 & 255 \\
\hline$\# 3 / 13.5$ & 5573 & 57.1 & 9760 \\
\hline$\# 3 / 20$ & 451 & 74.9 & 602 \\
\hline$\# 3 / 56.5$ & 177 & 93.4 & 190 \\
\hline$\# 3 / 81$ & 326 & 142.5 & 229 \\
\hline$\# 3 / 104$ & 408 & 169.3 & 241 \\
\hline$\# 3 / 129.5$ & 358 & 243.3 & 147 \\
\hline$\# 3 / 154$ & 169 & 160.1 & 106 \\
\hline$\# 4 / 22$ & 9000 & 61.9 & 14,540 \\
\hline$\# 4 / 37$ & 853 & 68.0 & 1254 \\
\hline$\# 4 / 49$ & 226 & 42.7 & 529 \\
\hline$\# 4 / 64.5$ & 173 & 73.9 & 234 \\
\hline$\# 4 / 86$ & 103 & 79.2 & 130 \\
\hline$\# 4 / 98$ & 204 & 96.5 & 211 \\
\hline$\# 4 / 99$ & 215 & 111.1 & 194 \\
\hline$\# 4 / 107.5$ & 32 & 30.5 & 105 \\
\hline$\# 4 / 118.5$ & 91 & 87.9 & 104 \\
\hline$\# 4 / 131.5$ & 68 & 78.4 & 87 \\
\hline \#4/143 & 89 & 88.4 & 101 \\
\hline$\# 4 / 153$ & 14 & 13.4 & 104 \\
\hline
\end{tabular}

${ }^{1}$ Propofol glucuronide, creatinine and normalized propofol concentrations in urine specimens collected from four individuals following 14 daily doses of sub-therapeutic $(50 \mathrm{mg})$, orally ingested propofol. Subjects consisted of two males and two females between the ages of $45-65$ years old and $150-300$ lbs. ${ }^{2}$ Normalized PPFG concentrations are normalized to $100 \mathrm{mg} / \mathrm{dL}$ creatinine. 
Table 2. Urinary propofol glucuronide resulting from incidental exposure: pilot study \#2. ${ }^{1}$.

\begin{tabular}{|c|c|c|c|}
\hline Subject & $\begin{array}{c}\text { PPFG } \\
(\mathrm{ng} / \mathrm{mL})\end{array}$ & $\begin{array}{l}\text { Creatinine } \\
(\mathrm{mg} / \mathrm{dL})\end{array}$ & $\begin{array}{c}\text { Normalized } \\
\operatorname{PPFG}^{2}(\mathrm{ng} / \mathrm{mL})\end{array}$ \\
\hline$\# 1$ & 0.06 & 124.2 & 0.05 \\
\hline$\# 2$ & 0.03 & 136.3 & 0.02 \\
\hline$\# 3$ & 0.07 & 94.5 & 0.07 \\
\hline$\# 4$ & 0.05 & 159.3 & 0.03 \\
\hline$\# 5$ & 1.00 & 45.4 & 2.20 \\
\hline$\# 6$ & 0.01 & 28.6 & 0.04 \\
\hline$\# 7$ & 0.58 & 146.8 & 0.40 \\
\hline$\# 8$ & 0.02 & 68.5 & 0.03 \\
\hline$\# 9$ & 0.03 & 91.0 & 0.03 \\
\hline$\# 10$ & 0.01 & 50.6 & 0.02 \\
\hline \#11 & 0.05 & 112.0 & 0.05 \\
\hline$\# 12$ & 0.01 & 188.9 & 0.01 \\
\hline$\# 13$ & 0.01 & 36.2 & 0.03 \\
\hline$\# 14$ & 0.32 & 213.6 & 0.15 \\
\hline \#15 & 7.24 & 158.1 & 4.58 \\
\hline$\# 16$ & 0.02 & 65.9 & 0.03 \\
\hline$\# 17$ & 1.35 & 151.2 & 0.89 \\
\hline$\# 18$ & 11.2 & 64.6 & 17.34 \\
\hline$\# 19$ & 0.03 & 89.7 & 0.03 \\
\hline$\# 20$ & 0.44 & 126.6 & 0.35 \\
\hline$\# 21$ & 0.05 & 94.7 & 0.05 \\
\hline$\# 22$ & 0.01 & 48.6 & 0.02 \\
\hline$\# 23$ & 0.12 & 92.8 & 0.13 \\
\hline$\# 24$ & 0.65 & 194.0 & 0.34 \\
\hline$\# 25$ & 0.52 & 206.9 & 0.25 \\
\hline$\# 26$ & 0.50 & 178.2 & 0.28 \\
\hline$\# 27$ & 0.45 & 201.7 & 0.22 \\
\hline
\end{tabular}

${ }^{1}$ Propofol glucuronide, creatinine and normalized propofol concentrations in urine specimens collected from nurse anesthetists immediately following 8 hour shifts in surgical rooms during the use of propofol for patient anesthesia. ${ }^{2}$ Normalized PPFG concentrations are normalized to $100 \mathrm{mg} / \mathrm{dL}$ creatinine.

demonstrate easily measurable excretion of PPFG as far out as 28 days (Table 3 and Figure 2).

The data from our oral ingestion pilot study \#1 (Table 1) also showed clearly measurable levels of urinary PPFG excretion as far as 6.4 days (154 hours) postdosing (Figure 1) in line with the results from Bleeker
Table 3. Propofol glucuronide, creatinine and normalized propofol concentrations in urine specimens collected following anesthetic induction and maintenance with propofol.

\begin{tabular}{cccc}
\hline Subject & $\begin{array}{c}\text { PPFG } \\
(\mathrm{ng} / \mathrm{mL})\end{array}$ & $\begin{array}{c}\text { Creatinine } \\
(\mathrm{mg} / \mathrm{dL})\end{array}$ & $\begin{array}{c}\text { Normalized } \\
\mathrm{PPFG}^{1}(\mathrm{ng} / \mathrm{mL})\end{array}$ \\
\hline 1 & 1656 & 16.9 & 9799 \\
4 & 627 & 13.1 & 4786 \\
9 & 1026 & 34.3 & 2991 \\
10 & 268 & 10.0 & 2680 \\
11 & 282 & 14.3 & 1972 \\
12 & 200 & 19.4 & 1031 \\
14 & 149 & 21.3 & 700 \\
17 & 141 & 20.0 & 705 \\
18 & 204 & 30.0 & 680 \\
21 & 679 & 100.0 & 679 \\
22 & 27 & 10.0 & 270 \\
26 & 49 & 40.0 & 123 \\
28 & 11 & 10.0 & 110 \\
\hline
\end{tabular}

${ }^{1}$ Normalized PPFG concentrations are normalized to $100 \mathrm{mg} / \mathrm{dL}$ creatinine.

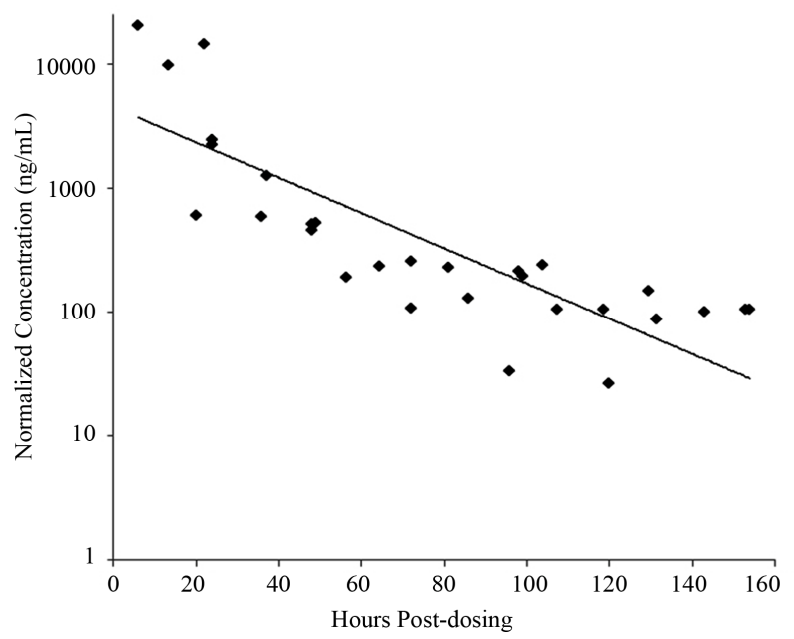

Figure 1. Disappearance profile of urinary propofol glucuronide following 14 daily sub-therapeutic $(50 \mathrm{mg})$ doses by oral ingestion: pilot study \#1.

et al. (2008). The oral ingestion data is interesting, in that even at sub-therapeutic doses (50 mg daily) delivered through the highly acidic stomach compartment, appreciable recovery of urinary PPFG was observed, perhaps suggesting that deep tissue storage (i.e. fat reserves, muscle tissues) of propofol occurs very quickly following dosing, and lasts much longer than previous data have suggested. 


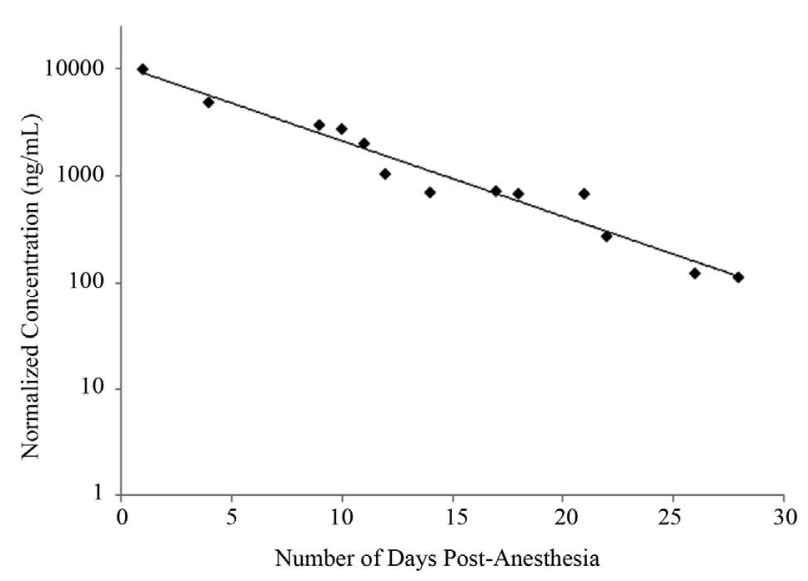

Figure 2. Disappearance profile of urinary propofol glucuronide following intravenous induction and maintenance of anesthesia.

Bleeker et al. (2008) hypothesized that renal reuptake, presumably following release from sequestration in deep tissues, and subsequent renal glucuronidation play a major role in terminal elimination of propofol, and the results presented here suggest their hypothesis is worth closer pharmacokinetic investigation [8], though glucuronidation may just as likely occur by the hepatic pathway after rerelease. PPFG, like propofol, is highly lipophilic, and the long-term excretion profile observed here may be from slow release of both propofol and PPFG, with subsequent conjugation of the parent compound. Further study is necessary to completely elucidate the exact nature and timing of storage and release.

\subsection{Propofol vs. PPFG for the Detection of Propofol Use and Abuse}

Despite its narrow therapeutic window [7] propofol has a high potential for abuse among healthcare professionals with access to propofol stocks [18], and propofol abuse has become a concern in the healthcare community [6]. The addictive nature of propofol has been previously demonstrated $[19,20]$, and several fatalities due to acute intoxication without respiratory monitoring have occurred [10-14]. Data suggests that second-hand exposure to propofol is high in hospital operating rooms and may cause sensitization from chronic exposure, potentially leading to an increased risk for use and abuse by anesthesia and surgical professionals [21,22]. More attention to inventory control for propofol stocks may be warranted [6], and screening to prevent non-procedural misuse and abuse by healthcare professionals with access may be needed. Recent research has shown that the course of propofol dependence can be rapid, and is often accompanied by frequent physical injury of the user [23]. Although the population of propofol abusers is low, that group carries the additional burden of a fatality rate $(28 \%)$ that is extremely high when compared with any traditional substance of abuse [6]. The importance of clear identification of propofol abuse in at risk healthcare professionals cannot be overstated.

The results shown here, along with those from Bleeker et al. (2008), demonstrate that PPFG is a more reliable biomarker for propofol abuse testing and monitoring than propofol itself. Although propofol and PPFG have been detected in several matrices including blood, urine, and hair [24], as well as in fingernails by our laboratory group (data not shown), a 28 day window of detection in urine, as is shown here, would be more than sufficient as the most cost-effective and efficient method of screening. Patterns of addiction seen with propofol indicate abuse of the compound involves multiple injections on frequent occasions [10-14,20,23], and it is highly unlikely the urinary PPFG profile for such behavior would show faster terminal elimination from the body than is seen in both the anesthetic and oral ingestion datasets presented here (Figures 1 and 2).

Data from pilot study \#2 involving nurse anesthetists shows that passive exposure to aerosolized propofol in the surgical environment provides a urinary PPFG profile that is much different, and easily distinguishable, from that of a person who has been administered the anesthetic regardless of the route of administration. This suggests that it should be easy to identify propofol abusers from the general population of anesthesia professionals, and a positive result cutoff of $200 \mathrm{ng} / \mathrm{mL}$ in urine specimens should be sufficient to identify a person who is misusing propofol for recreational purposes.

\section{Conclusion}

The results presented here demonstrate that PPFG has a very long and robust disappearance profile in urine, and has the potential to easily distinguish propofol abusers from the greater population of healthcare professionals. To our knowledge, this is the longest window of detection that has been demonstrated following propofol ingestion of any sort. Propofol has a high potential for abuse and is increasingly a cause for concern in the healthcare community, and routine testing of healthcare professionals with access to the compound may be warranted. Lack of scheduling by the United States Drug Enforcement Administration has resulted in easy and under-regulated access to propofol in most hospitals where no inventory control is present. Propofol itself has a very short window of detection in blood and urine, and the data presented here suggest that measuring PPFG in urine samples is an efficient and reliable tool for routine screening for propofol use and abuse. 


\section{REFERENCES}

[1] C. M. Smith and A. M. Reynard, "Textbook of Pharmacology," Harcourt Publishers Ltd., San Diego, 1992.

[2] A. Gupta, T. Stierer, R. Zuckerman, N. Sakima, S. D. Parker and L. A. Fleisher, "Comparison of Recovery Profile after Ambulatory Anesthesia with Propofol, Isoflurane, Sevoflurane and Desflurane: A Systematic Review," Anesthesia \& Analgesia, Vol. 98, No. 3, 2004, pp. 632641.

http://dx.doi.org/10.1213/01.ANE.0000103187.70627.57

[3] E. I. Eger, "Characteristics of Anesthetic Agents Used for Induction and Maintenance of General Anesthesia," American Journal of Health-System Pharmacy, Vol. 61, Suppl. 4, 2004, pp. S3-S10.

[4] B. Fulton and E. M. Sorkin, "Propofol. An Overview of Its Pharmacology and a Review of Its Clinical Efficacy in Intensive Care Sedation," Drugs, Vol. 50, No. 4, 1995, pp. 636-657.

http://dx.doi.org/10.2165/00003495-199550040-00006

[5] J. Kanto and E. Gepts, "Pharmacokinetic Implications of the Clinical Use of Propofol," Clinical Pharmacokinetics, Vol. 17, No. 5, 1989, pp. 308-326.

http://dx.doi.org/10.2165/00003088-198917050-00002

[6] P. E. Wischmeyer, B. R. Johnson, J. E. Wilson, C. Dingmann, H. M. Bachman, E. Roller, Z. V. Tran and T. K. Henthorn, "A Survey of Propofol Abuse in Academic Anesthesia Programs," Anesthesia \& Analgesia, Vol. 105, No. 4, 2007, pp. 1066-1071. http://dx.doi.org/10.1213/01.ane.0000270215.86253.30

[7] C. F. Ward, "Propofol: Dancing with the 'White Rabbit'," Bulletin of the California Society of Anesthesiology, Vol. 57, No. 2, 2008, pp. 61-63.

[8] C. Bleeker, T. Vree, A. Lagerwerf, and E. Williams-van Bree, "Recovery and Long-Term Renal Excretion of Propofol, Its Glucuronide, and Two Di-Isopropylquinol Glucuronides after Propofol Infusion during Surgery," British Journal of Anaesthesia, Vol. 101, No. 2, 2008, pp. 207212. http://dx.doi.org/10.1093/bja/aen134

[9] P. Favetta, C. S. Degoute, J. P. Perdrix, C. Dufresne, R. Boulieu and J. Guitton, "Propofol Metabolites in Man Following Propofol Induction and Maintenance," British Journal of Anaesthesia, Vol. 88, No. 5, 2008, pp. 653-658. http://dx.doi.org/10.1093/bja/88.5.653

[10] O. H. Drummer, "A Fatality Due to Propofol Poisoning," Journal of Forensic Science, Vol. 37, No. 4, 1992, pp. 1186-1189.

[11] T. C. Chao, D. S. Lo, P. P. Chui and T. H. Koh, "The First Fatal 2, 6-Di-Isopropylphenol (Propofol) Poisoning in Singapore: A Case Report," Forensic Science International, Vol. 66, No. 1, 1994, pp. 1-7. http://dx.doi.org/10.1016/0379-0738(94)90314-X

[12] S. Iwersen-Bergmann, P. Rosner, H. C. Kuhnau, M. Junge and A. Schmoldt, "Death after Excessive Propofol Abuse," International Journal of Legal Medicine, Vol. 114, No. 4-5, 2001, pp. 248-251. http://dx.doi.org/10.1007/s004149900129

[13] E. F. Kranioti, A. Mavroforou, P. Mylonakis and M. Mi- chalodimitrakis, "Lethal Self Administration of Propofol (Diprivan). A Case Report and Review of the Literature," Forensic Science International, Vol. 167, No. 1, 2007, pp. 56-58. http://dx.doi.org/10.1016/j.forsciint.2005.12.027

[14] G. Klausz, K. Rona, I. Kristof and K. Toro, "Evaluation of a Fatal Propofol Intoxication Due to Self Administration," Journal of Forensic and Legal Medicine, Vol. 16, No. 5, 2009, pp. 287-289. http://dx.doi.org/10.1016/j.jflm.2008.12.010

[15] H. M. Bryson, B. R. Fulton and D. Faulds, "Propofol. An Update of Its Use in Anesthesia and Conscious Sedation," Drugs, Vol. 50, No. 3, 1995, pp. 513-559. http://dx.doi.org/10.2165/00003495-199550030-00008

[16] W. R. Needleman, M. Porvaznik and D. Ander, "Creatinine Analysis in Single Collection Urine Specimens," Journal of Forensic Sciences, Vol. 37, No. 4, 1992, pp. $1125-1133$

[17] “DRI ${ }^{\circledR}$ Creatinine-Detect Test," Product Insert, Microgenics Corporation, Fremont, 2005.

[18] O. Grundmann, "Propofol: An Analytical and MedicoLegal Challenge," Forensic Magazine, Vol. 7, No. 5, 2010, pp. 13-15.

[19] J. P. Zacny, J. L. Lichtor, W. Thompson and J. L. Apfelbaum, "Propofol at a Subanesthetic Dose May Have Abuse Potential in Healthy Volunteers," Anesthesia and Analgesia, Vol. 77, No. 3, 1993, pp. 544-552. http://dx.doi.org/10.1213/00000539-199309000-00020

[20] U. Bonnet, J. Harkener and N. Scherbaum, "A Case Report of Propofol Dependence in a Physician," Journal of Psychoactive Drugs, Vol. 40, No. 2, 2008, pp. 215-217. http://dx.doi.org/10.1080/02791072.2008.10400634

[21] P. F. McAuliffe, M. S. Gold, L. Baipai, M. L. Merves, K. Frost-Pineda, R. M. Pomm, B. A. Goldberger, R. J. Melker and J. C. Cendan, "Second-Hand Exposure to Aerosolized Intravenous Anesthetics Propofol and Fentanyl May Cause Sensitization and Subsequent Opiate Addiction among Anesthesiologists and Surgeons," Medical Hypotheses, Vol. 66, No. 5, 2006, pp. 874-882. http://dx.doi.org/10.1016/j.mehy.2005.10.030

[22] L. J. Merlo, B. A. Goldberger, D. Kolodner, K. Fitzgerald and M. S. Gold, "Fentanyl and Propofol Exposure in the Operating Room: Sensitization Hypotheses and Further Data," Journal of Addictive Disorders, Vol. 27, No. 3, 2008, pp. 67-76. http://dx.doi.org/10.1080/10550880802122661

[23] P. H. Earley and T. Finver, "Addiction to Propofol: A Study of 22 Treatment Cases," Journal of Addiction Medicine, Vol. 7, No. 3, 2013, pp. 169-176. http://dx.doi.org/10.1097/ADM.0b013e3182872901

[24] V. Cirimele, P. Kintz, S. Doray and B. Ludes, "Determination of Chronic Abuse of the Anesthetic Agents Midazolam and Propofol as Demonstrated by Hair Analysis," International Journal of Legal Medicine, Vol. 116, No. 1, 2002, pp. 54-57.

http://dx.doi.org/10.1007/s004140100240 